\title{
UN ESCAP과 개발협력
}

박 수 영 / ESCAP NRL 전문가

\section{ESCAP 설립}

제 2 차 세계대전 이후 전후 피해지역에 대한 복구 및 지원을 위해 유엔 경제사회이사회(Economic and Social Council: ECOSOC)는 1946년 6월 21 일 결의(2/6)를 통해 '유럽을 위한 실무그룹' 과 '아시아 - 극동을 위한 실무그룹' 으로 구성된 임시 소위원회를 설치하였다. 1946년 12월 11일 United Nations(UN) 총회 (General Assembly: GA)는 동 임시 소위원회의 예비보고서에 기초하여, $\mathrm{ECOSOC}$ 산하에 유럽경제위원회(Economic Commission for Europe : ECE)와 아시아 · 극동 경제위원회(Economic Commission for Asia and the Pacific : ECAFE)의 설립을 권고하고, $\mathrm{ECOSOC}$ 은 1947년 3월 28일 결의(E/405)에 의 거 $\mathrm{ESCAP}$ 의 전신인 아시아 - 극동경제위원회, 즉 $\mathrm{ECAFE}$ 를 중국 상하이에 설립하였다.
설립 초기는 활동이 미약하였으나, 이후 아시아 및 태평양 도서개도국이 회원으로 참여하면서 지역범 위가 확대되고, 관련분야도 경제개발에서 경제, 사 회 개발로 사회문제의 중요성이 대두되면서 1974 년 명칭을 ESCAP (Economic and Social Commission for Asia and the Pacific)으로 변경 하며, 아시아 태평양지역의 경제 및 사회문제 전반 을 아우르는 기구로 오늘에 이르게 된다. 현재 $\mathrm{ESCAP}$ 은 뉴욕에 있는 UN 본부의 경제사회이사 회(Economic and Social Council)에 속하는 5개 지역위원회(Regional Commissions)중 세계전체 의 약 $62 \%$ 에 해당하는 38 억의 인구를 차지하는 가장 큰 지역위원회이다. 경제면에서도 ESCAP지 역 내 개도국의 경제성장률은 2005년 7.6\%, 2006 년 7.9\%로 전 세계 평균경제성장율(4\%이하) 또는 다른 지역의 성장률보다 높아 $\mathrm{ESCAP}$ 이 담당하는 지역은 가장 역동적인 세계경제 성장 동력이라고 할 수 있다. 


\section{II . ESCAP 업무범위}

$\mathrm{ECOSOC}$ 이 결의한 $\mathrm{ESCAP}$ 의 업무범위는 다음과 같다.

- 아시아 - 극동의 경제재건과 개발을 위한 공동 노력을 촉진하고, 동 지역의 경제 활동수준을 향상시키며, 지역 내 - 외 국가 간 경제관계를 유지 · 강화하기 위한 조치를 주도하거나 이에 참여한다.

- 아시아 - 극동 지역 내 경제적 - 기술적 문제와 개발에 관한 조사가 필요하다고 판단되는 경 우 이를 실시 또는 지원한다.

- 경제 · 기술 - 통계 정보의 수집 · 평가 · 확산 이 필요시, 이를 실시 또는 지원한다.

- 사무국의 가용한 자원 범위 내에서 지역 국가 들이 희망하는 자문기능(advisory services) 을 수행한다. 단, 이러한 기능이 유엔 전문기 구 또는 유엔 기술원조청(UNTAA)의 기능과 중복되지 않아야 한다.

- ECOSOC이 요청하는 경우 지역 내에서 기술 지원 문제를 포함하여 경제 문제관련 사항을 수행하는 것을 지원한다.

2005년 이후 ESCAP은 3개의 Thematic area를
설정하고 상기 분야별 위원회를 개최하며, 사무국 내 실무국 활동을 상기 3 개 분야 중 하나에 속하도 록 통합하였다.

- 빈곤감소(Poverty Reduction): 아 - 태지역내 빈곤감소를 위한 우수사례 수집과 전파를 촉 진한다.

- 세계화 관리(Managing Globalization): 회원 국 및 준회원이 세계화의 도전에 적극적으로 대응할 수 있도록 무역 및 환경 분야의 협상기 술 향상에 주력한다.

- 신사회이슈에 대한 대응(Tackling Emerging Social Issues): 지역 내 새로운 사회문제에 대처하고, 장애인 지원, 보건 및 남녀평등과 관련한 사업을 강화한다.

\section{III. $\mathrm{ESCAP}$ 의 구조 및 운영}

$\mathrm{ESCAP}$ 은 $\mathrm{ECOSOC}$ 산하의 지역이사회 중 하나로 서, 최고협의체인 총회, $\mathrm{ESCAP}$ 이 추진하는 3 개 주제별 위원회, 상기 총회와 위원회의 결의사항 및 $\mathrm{ACPR}$ 의 논의사항들을 실제 수행하는 $\mathrm{ESCAP}$ 사 무국, 그리고 사무국과 회원국사이의 의견교환 채 널인 $\mathrm{ACPR}$ 로 크게 구성된다. 각 조직별 업무내용 은 〈그림 1)과 같다. 
〈그림 1〉 ESCAP의 구조 및 운영(2007년 10월 현재)

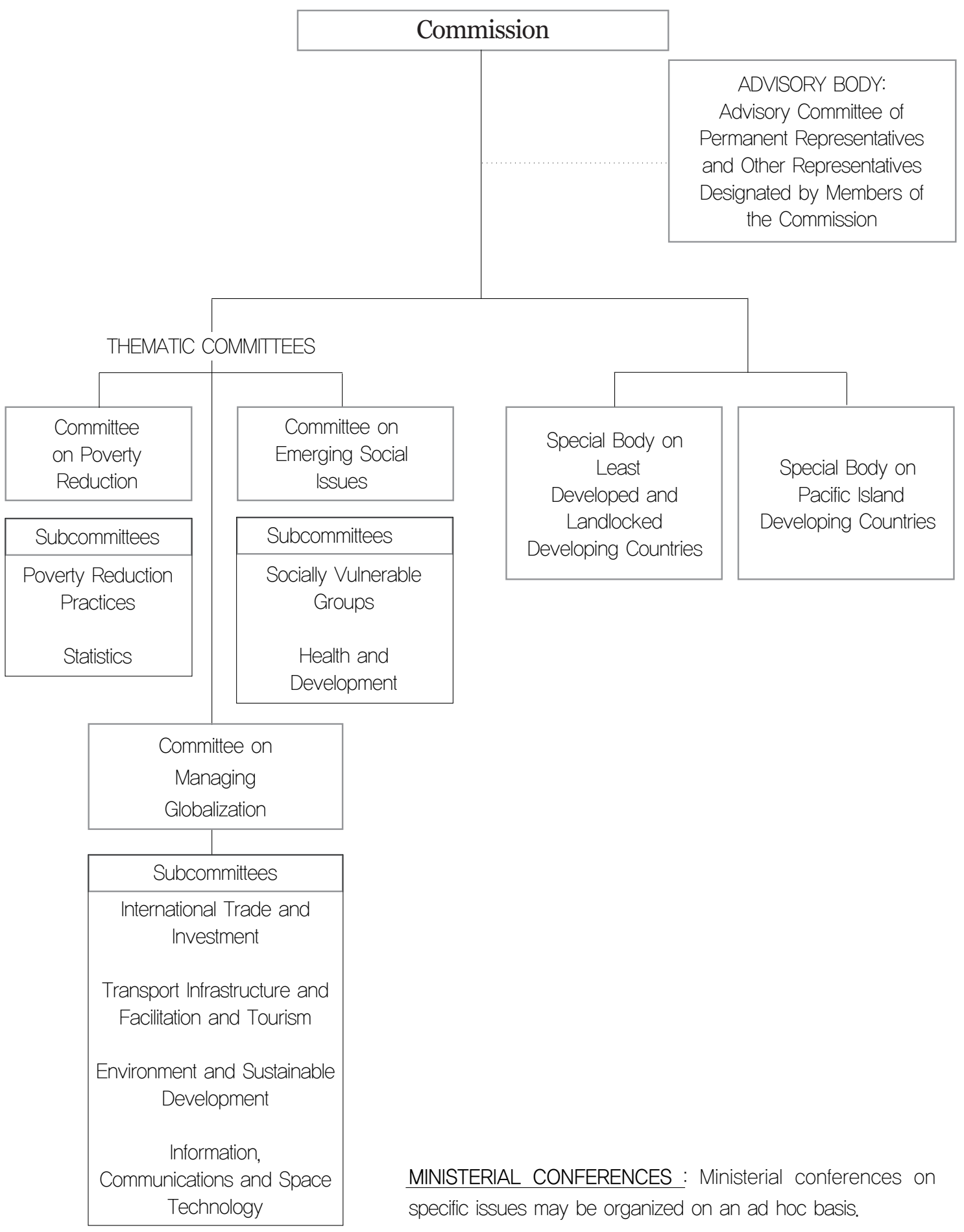




\section{1. 의사결정기구}

\section{가. 총회 (Commission)}

- $\mathrm{ESCAP}$ 의 주협의기구인 총회(Commission) 는 매년 장관급 회의로 개최되며, 모든 회원 국들이 참석한 가운데 경제·사회이슈를 토 론하고 지역협력 강화방안을 논의한다. 동 회 의 결과는 매년 $\mathrm{ECOSOC}$ 에 보고되며, $\mathrm{ESCAP}$ 이 향후 사업계획, 추진방향 등 전체 적인 전략을 수립하고, 사업추진결과를 보고 하는 장이 된다.

\section{나. 상 주 대 표 자 문 위 원 회 (Advisory} Committee of Permanent Representatives and other Representatives Designated by Members of the Commission: ACPR)

- 상주대표 자문위원회는 1974년 설치되었고, 회원국과 준회원국의 대표로 구성된다. 통 상적으로 “ACPR"로 불리며, 거의 매달 개 최되어 $\mathrm{ESCAP}$ 의 활동에 관해 총장 및 사무 국과 회원국 간에 의견을 교환하는 기능을 수행한다.

\section{2. 주제별 위원회 (Thematic Committee)}

- 총회의 산하에는 ESCAP의 3 개 Thematic
Area에 따라 3 개 주제별 위원회와 2개의 special body가 설치되어 있으며, 사무국의 각 부서는 3 개 주제별 위원회 중 하나의 주제 에 속한다.

\section{3. 특별기구}

- 최근 개발논의에서 최빈개도국 및 내륙개도 국, 도서개도국이 경제·사회 개발에 있어서 갖는 특별한 문제점과 제약이 대두되었고, 이 에 따라, 에스캅은 "최빈국 및 내륙개도국에 관한 특별기구(Special Body on Least Developed and Landlocked Developing Countries)와 태평양도서개도국에 관한 특별 기구 (Special Body on Pacific Island Developing Countries)를 두어 현재 진행 중 인 지역 내 통합과정에서 상기 국가들의 취약 성 및 특수성을 대응하기 위한 포럼을 제공한 다. 이 2개의 특별기구는 $\mathrm{ESCAP}$ 총회와 연계 하여 2일간 교대로 격년 개최된다.

\section{4. 사무국}

- 사무국은 크게 실무국과 사업지원국으로 구성 된다. 실무국으로는 빈곤 - 개발국(Poverty and Development Division), 통계국 (Statistics Division), 무역·투자국 (Trade and Investment Division), 교통 - 관광국 (Transport and Tourism Division), 환경 · 
지속개발국(Environment and Sustainable Development Division), 정보 · 통신 · 우주기 술국 (Information, Communication and Space Technology Division), 신사회이슈국 (Emerging Social Issues Division)이 있으 며, 사업지원국으로는 뉴욕본부와의 업무보 고, 사업기획, 평가 등을 담당하는 사업관리국 (Programme Management Division)과 인 사, 재무, 총무를 담당하는 행정서비스국 (Administrative Service Division)이 있다.

\section{ESCAP의 주요 활동내용}

ESCAP은 UN 본부의 mandate내에서 아 - 태 지 역 내 UN 문제를 자율적으로 결정 - 해결 - 집행해 나가는 UN 지역본부로서 경제, 사회, 금융 등 포 괄적 분야에 걸쳐 업무 수행해나가는 각료급 의사 결정기구로, 현재 $\mathrm{ESCAP}$ 의 역할은 크게 세 가지 로 구분된다고 할 수 있다. 첫째는 $\mathrm{ECOSOC}$ 의 지 역이사회로써, 아시아 태평양 지역의 사회 및 경제 문제에 대해 총회 및 분야별 회의 개최를 통해 토 론과 정보교환의 장 역할, 두 번째는 관할 지역 내 의 사회 및 경제개발 문제에 대한 자료수집 및 동 향 분석 등을 통한 규범 및 분석적 역할 (normative and analytical work), 세 번째는 실 질적인 기술협력(technical cooperation) 수행이 다. 다음에서 국제협력단과 많은 관계를 갖는 기 술협력사업에 대해 보다 자세히 설명하겠다.

\section{ESCAP의 기술협력사업}

\section{1. 개요}

ESCAP은 설립 당시 연구 - 자문기구로서 주로 간 주되었지만, 시간이 지나면서 점차 현장의 개발활 동에 참여하게 되어, 1974년 800만불 규모에 불과 하였으나, 2006년에는 총 1,450 만불이 되었다. 예 산의 $47.2 \%$ 는 회원국의 자발적 기여이며, 유엔 정 규예산(Section 22) 16\%, UN Development Account 15.7\%, UNDP 7.8\%, UN Population Fund $2.6 \%$, 기타 정부간 - 비정부간 기구 기여 $10.7 \%$ 이다. 2006년 회원국이 제공한 자발적 기 여금 총액은 685 만불이며, 주요 기여국은 일본 (213.4만불), 한국 (188.6만불), 중국(80.7만불), 스 웨덴(80만불), 인도(38만불), 독일(26.6만불) 등이 다. 정부간 - 비정부간 기구의 기여 총액은 155 만 불이며, 주요 기여기관은 아시아개발은행(ADB: 75만불), 국제개발연구센터(IDRC: 23 만불), 세계 무역기구(WTO: 16만불), 유럽공동체(EC: 11.9만 불) 등이다. 현물 기여로서 연 148개월(workmonths)의 다양한 분 야 전 문 가 (Non Reimbursable Loan Expert)가 제공되었으며, 이 중 $81 \%$ 는 한국정부로부터 제공되었다. 2006년 $\mathrm{ESCAP}$ 사무국의 기술협력 집행실적은 약 1,350 만불이며, 이중 회원국 또는 기타 기관의 자발적 기여금이 1,070 만불이다. 유엔 기술협력 정규사업 (section 22)하에서 실시되는 기술협력은 178만불 이며, 이중 $70 \%$ 이상은 최빈국, 내륙개도국, 태평 
양 개도국, 경제체제전환국 등 43 개국에 대한 59 개 자문단 파견에 사용되었으며, 나머지 $30 \%$ 는 남 남협력(South-South cooperation)의 맥락에서 이루어지는 기술협력을 포함하여 지역훈련활동 및 fellowships을 이행하는데 사용되었다.

\section{2. 추진절차}

$\mathrm{ESCAP}$ 의 기술협력사업 추진 절차는 전체적으로 는 다른 개발협력기관과 크게 다르지 않으나 실제 수행과정상에서 UN기관 또는 지역이사회라는 기 관 자체의 특수성에 기인한 실무적인 차이점이 많 이 있다.

\section{가. 사업형성 및 심사}

- 일반적으로 프로젝트는 공여기관 또는 공여국 이 예산 지원의사를 밝히면서 시작된다. $\mathrm{ESCAP}$ 과 공여기관이 구두 협의를 통해 사업 예산, 분야 등에 대해 초안을 협의하면, ESCAP의 실무국은 협의사항에 따라 Project Profile이라고 불리우는 사업개요서를 작성하 여 내부심사 과정을 거쳐 공여국에 제출된다.

\section{나. 사업계획}

- 공여국이 결정된 Project Profile은 다시 실무 국으로 넘겨져 사업기획 단계로 넘어간다. Project Profile은 확정된 예산 및 수원국 등
에 따라 Project Document로 심화, 발전되게 되어 총장의 승인을 받게되면, 공여국에 제출 되고, 이를 기초로 공여국과 ESCAP간 사업추 진을 공식화 하는 Agreement를 체결하게 된 다. Agreement가 체결되고 나면, ESCAP은 공여국에 사업예산을 신청하고, 동 예산은 뉴 욕UN본부를 거쳐 방콕으로 전달된다. 실무국 은 지원된 예산에 대한 예산배분요청서 (Allotment Request)를 PMD에 보내서 예산 을 사용할 수 있도록 프로젝트계좌(Project Account)를 배정받는다. 예산 사용이 가능해 지면, 실무국은 사전조사 등을 통해 수원국과 사업을 협의한 뒤, Letter of Agreement $(\mathrm{LoA})$ 를 체결하여, 수원국과 ESCAP간 사업추진을 공식화 한다.

\section{다. 사업실행 및 종료}

- LoA체결로 사업추진이 공식화되면, ESCAP 은 추가 조사를 통해 세부적인 Action $\mathrm{Plan}$ (사업세부계획서)를 작성하고, 동 계획서 에 따라, 수원기관과 함께 사업을 추진한다. 한편 ESCAP 실무국은 Agreement에 따라, 반기별 보고서를 작성하고 $\mathrm{PMD}$ 를 통해 공여 국에 제출하며, 사업계획의 변경이 있을시에 는 역시 PMD를 통해 Amendment를 통해 LoA와 Agreement를 수정한다. 사업이 종료 되면 $\mathrm{ESCAP}$ 은 종료 6 개월 이내에 종료보고 서를 공여국에 제출한다. 


\section{기술협력사업 추진관련 주요 문서}

1. Project Profile: 사업심사를 위해 사업형성 단계에서 작성하는 간략한 사업개요서

2. Project Document: Project Profile을 심화한 사업계획서

3. Trust Fund Agreement: 공여기관과 체결하는 협정서

4. Letter of Agreement: 수원기관과 체결하는 사업추진 협의서

5. Memorandum of Understanding: 계약기관과 체결하는 약정서

6. Progress Report: 공여기관에 반기별로 제출하는 중간보고서

7. Terminal Report: 공여기관에 사업종료시 제출하는 종료보고서

\section{UN개혁과 ESCAP}

2006년 UN은 개발분야에 대한 유엔 개혁 기획 보 고서인 "Delivering as One"을 발표하고, 유엔시 스템내의 유엔기구, 펀드 및 프로그램의 수원국내 의 중첩되며 상이한 활동을 지양하고 UNDP 중심 의 체계화된 개발협력 노력 강화 의지를 천명한 바 있으며, 이에 따라 아시아에서는 베트남, 몽골이 그 첫 번째 시범대상국으로 선정되어 단일 채널을 통한 협력방안을 시험 중이다. $\mathrm{ESCAP도} \mathrm{이러한}$ $\mathrm{UN}$ 시스템내의 변화하는 상황에 맞춰 이미 두차례 외부 평가를 시행한 바 있으며, 현재 다양한 개혁 안을 작성하여 회원국과 협의 중이다.

\section{VII. 한국과 $\mathrm{ESCAP}$ 간의 협력}

우리나라는 ESCAP과 지속적인 협력관계를 유지, 발전 시켜왔으며, 개발관련 대표적인 사례는 KECF (Korea ESCAP Cooperation Fund)를 들
수 있다. 우리나라는 1987년 9월 ESCAP과 협력 기금 설치에 관한 양해각서를 체결하고, 1987 년 이후 2006년까지 912 만불의 자발적 기여금을 제 공하였다. $\mathrm{KECF}$ 협력사업은 상설 신탁기금 $(\mathrm{KECF})$ 에 매년 기여금을 예치한 후 이 신탁기금 에서 사업비를 지출하게 되며, 사업별 잔액이 발생 할 경우에는 동 신탁기금에 재적립 된다. 상기 양 해각서 규정에 따라 한국정부는 매년 40만불 내외 의 기금을 제공하고, 양측간 연례회의(통상적으로 12 월 개최)에서 신규사업을 검토, 승인하고 기존사 업의 진전사항을 점검하고 있다.

\section{KOICA-ESCAP 향후 협력 방안}

$\mathrm{ESCAP}$ 은 유엔사무국 산하의 아 - 태 지역 이사회 로서 동 지역의 사회 경제 문제에 대한 정보수집 및 연구, 지역별 차원의 문제 해결을 위해 회원국 정부 대표들을 통한 의견교환을 고유의 주된 업무 로 한다. 따라서, $\mathrm{KOICA}$ 는 향후 $\mathrm{ESCAP}$ 과의 협 력방안을 고려시 이러한 $\mathrm{ESCAP}$ 의 업무성격을 고 려하여 상호 이익을 얻을 수 있는 협력방안을 모색 해야 할 것이다. 예를 들어, $\mathrm{ESCAP}$ 의 총회나 위 원회는 아 - 태 지역의 개발이슈에 관한 최신 협력 동향을 알 수 있는 토론의 장인 바, 관련 위원회에 참여하여 개발동향에 대한 정보를 수집하고 타 공 여국이나 수원국과의 협력방향을 모색하는 것은 $\mathrm{KOICA}$ 가 국제적 개발흐름에 맞춰 이슈를 선정하 고 정책을 개발하는데 도움이 될 것이다. 